\title{
Land set up systems and beyond: Influence of soil management on water and soil conservation sewed up to a variety of pedoclimatic environments and farming systems
}

\author{
Filiberto Altobelli, ${ }^{1}$ Marco Napoli, ${ }^{2}$ Anna Benedetti, ${ }^{1}$ Ronald Vargas, ${ }^{3}$ Giuseppe Corti ${ }^{4}$ \\ Guest editors \\ ${ }^{1}$ CREA Research Centre for Agricultural Policies and Bioeconomy, Rome; ${ }^{2}$ Department of Agriculture, \\ Food, Environment and Forestry (DAGRI), University of Florence; ${ }^{3}$ Land and Water Division, Food and \\ Agriculture Organization of the United Nations (FAO), Rome; ${ }^{4}$ Department of Agricultural, Food and \\ Environmental Sciences, Università Politecnica delle Marche, Ancona, Italy
}

\section{Concept note}

According to European Landscape Convention, the term Landscape means an area whose character is the result of the action and interaction of natural and human factors. The equilibrium between these forces is mandatory to preserve this heritage implementing a good land protection and conservation policy that implies many professional figures like agronomists and soil scientists. Italian territory includes different physiographic regions in which many human activities, especially agriculture, differently operated through the time. From a pedological point of view, by agriculture, man is a soil forming force that may cause soil changes through direct interventions such as manuring, liming, ploughing, fertilization, irrigation and through indirect interventions such as relief and drainage modification that change moisture regimes, and reclamation of natural soils after their deforestation. Unfortunately, great part of Italian land, especially the rural areas, is prone to water erosion and floods, which are considered the most critical forms of soil degradation in the European Community. With soil erosion, also crop quality and biodiversity are jeopardized. During time the topic of soil water erosion on cultivated land has received much concern, due to both the increase of problems caused by the erosion itself and the significant environmental and economic consequences. In Italy, erosion has been a problem since the Greek invasion (X century b.C.) and Roman scientists developed land setting to reduce it. However, it was from the XVIII century that agronomists gave their maximum contribution to mitigate erosion, developing a variety of land settings suitable for many pedoclimatic and geomorphic conditions. Further, if erosion may affect hill and mountain terri-

Correspondence: Filiberto Altobelli, CREA Research Centre for Agricultural Policies and Bioeconomy, via Po 14, 00198 Rome, Italy. Tel.: +39.06.47856568.

E-mail: filiberto.altobelli@crea.gov.it

Key words: Special issue; water and soil conservation; introduction.

Received for publication: 2 November 2020.

Accepted for publication: 3 November 2020.

${ }^{C}$ Copyright: the Author(s), 2020

Licensee PAGEPress, Italy

Italian Journal of Agronomy 2020; 15:1771

doi:10.4081/ija.2020.1771

This article is distributed under the terms of the Creative Commons Attribution Noncommercial License (by-nc 4.0) which permits any noncommercial use, distribution, and reproduction in any medium, provided the original author(s) and source are credited. tories, bottom valley and plain soils are often threatened by water stagnation due to impeded drainage. Also in these cases, different in function of their physiographic conditions, several land set-up systems were adopted to promote water discharge and diversify the crops.

This special issue recollects the most diffused and smart land settings adopted in the Italian territories, providing scientific information on their use and efficacy; when this is impossible because of the lack of experimentation, reflecting on the value of land settings on the base of the actual knowledge on the environment where they were applied. In addition, the aim is to highlighted the contribution of land set-up systems to improving the available soil water content and discuss the efforts of agronomists and soil scientists to find a balance between soil management techniques to combat erosion and to promote water conservation. We also report evidences on how the technological development (mechanisation) and agricultural development policies (need of crop intensification and specialisation, subsidies for the production of certain crops, etc.) have affected agricultural systems and, at the same time, land set-up systems over time.

The aim of this special issue is reported experiences to mitigate erosion and water shortage with the hope they can be adopted in environments like those where they were developed starting from outcome of the Food and Agriculture Organization (FAO) on Global, European and Italian Soil Partnership experiences to improve soil and water conservation by sustainable soil management practices.

Furthermore, several contributions present in this work come from the Global Symposium on Soil Erosion (GSER19), 'Stop soil erosion, Save our future' was held from 15-17 May 2019, at the UN FAO Headquarters in Rome, Italy. This science-policy meeting was coorganized by the UN FAO and its Global Soil Partnership (GSP), the Intergovernmental Technical Panel on Soils (ITPS), together with the Science-Policy Interface (SPI) of the UN Convention to Combat Desertification (UNCCD), and the Joint FAO/IAEA Programme of Nuclear Techniques in Food and Agriculture. The objective of GSER 19 was to establish a common platform to present and discuss the latest information on the status of interventions and innovations in the field of soil erosion and related land management.

Potential topics this special issue include but are not limited to the following: i) land set-up systems devoted to soil and water conservation in different Italian lands - mountain, hill, plain; ii) possible focus on soil types, soil orders, implications, effects; iii) importance of coupling land set-up systems and soil managements - examples in different physiographic agro-ecosystems; iv) effect of agronomic and economic development affecting farming systems, land organisation, and land setting systems. 